\title{
Abordagem lúdica das questões de física: história em quadrinhos sobre cinemática
}

Playful approach to physics questions: comics about kinematics

\author{
W. O. Cavalcante*; A. L. F. Novais; F. C. L. Ferreira \\ Programa de Pós-Graduação em Ensino de Física, Universidade Federal do Sul e Sudeste do Pará, 68500-000, \\ Marabá - PA, Brasil. \\ *dr.willamy@gmail.com
}

(Recebido em 04 de março de 2019; aceito em 18 de junho de 2019)

\begin{abstract}
Considera-se a física tem tudo para ser uma disciplina superinteressante, mas quando se fala em resolver questões, poucas são as metodologias diferenciadas que surgem. O uso de Histórias em Quadrinhos que já vêm divertindo e informando, pode também auxiliar em cálculos, com sua linguagem simples e universal. Constatado esse potencial, o presente trabalho tem por objetivo a utilização das Histórias em Quadrinhos como instrumento de ensino de física, atentando-se para o uso diferenciado nas resoluções de questões de cinemática na sala de aula. Os dados do estudo foram obtidos com alunos do Ensino Médio Semipresencial de educação de Jovens e Adultos. Os resultados de sua implementação das Histórias em Quadrinhos para $\mathrm{o}$ ensino de Cinemática foram satisfatórios quanto à apropriação da proposta para o interação e a aprendizagem dos alunos.

Palavras-chave: história em quadrinho, física, cinemática.
\end{abstract}

It is considered that physics has everything to be a superinteressing discipline, but when it comes to solving issues, it is like the differentiated methodologies that emerge. The use of comics that are already present and informing, can also be ancillary in calculations, with its simple and universal language. It is this potential, the present work has as use of Comic Histories as an instrument of physics teaching, with the purpose of using the resolutions in the questions of kinematics in the classroom. The data of the study were promoted with the Semipresential Middle School of Youths and Adults. The results of its implementation of the Comics for the teaching of English were satisfactory for the appropriation of the proposal of interaction and learning of the students.

Keywords: story in comic, physics, kinematics.

\section{INTRODUÇÃO}

O conteúdo da física é tido pelo aluno como desinteressante, de difícil entendimento e longe de sua realidade. Desta forma, o maior desafio do professor é tornar a física mais próxima da realidade do aluno, para que esta possua significado a ele. Os livros didáticos tradicionais, geralmente, são pouco atrativos, e os exercícios propostos apresentam pouquíssimas relações com seu cotidiano, assim, o aluno não consegue corriqueiramente ter a abstração necessária para que se faça uma questão proposta e é neste ponto que entra o presente artigo. Trabalhar com Histórias em Quadrinhos (HQs) em uma aula de física pode ser uma atividade estimulante e facilitadora da aprendizagem $[1,2]$.

Diante disso, percebeu-se a possibilidade da utilização de histórias em quadrinhos (HQs) e de que forma elas poderiam contribuir no efetivo entendimento/assimilação da questão proposta e incentivá-los a um maior envolvimento dos alunos, e, no presente trabalho, na internalização dos próprios conceitos da cinemática.

Em contraposição a uma instrução formal e ainda, em sua maioria, rígida, com as HQs além de poder atingir uma finalidade instrutiva também conseguem preencher uma finalidade educativa [3]. Por ser acessível e, possivelmente, ter sido o primeiro contato de leitura pela maioria dos alunos, as HQs tornam-se muito importantes como material de ensino, possibilitando a ampliação de comunicação dos alunos e suas várias utilizações possíveis são evidentes, pois elas propiciam uma diversidade de temas atendendo a diferentes gostos e contribuindo para a formação de valores 
e o exercício da cidadania desenvolvendo significativamente a leitura e a escrita de forma lúdica e aprazível [4].

Diante disso, percebe-se que têm características universais, por exemplo, a formatação dos quadrinhos, linguagem de fácil assimilação com enredo simples, além do apelo visual e gráfico. Desta forma, as HQs são meios de comunicações bem conhecidos e influenciaram várias gerações entre estudantes de qualquer nível de escolaridade graças a esses vários atrativos disponíveis, usada adequadamente no ensino, elas têm o poder de chamar atenção do aluno à leitura, aumentando a motivação e a curiosidade para os conteúdos, assim como, a sua participação e, consequentemente, o seu senso crítico [5]. Motivando-os a produzir histórias em quadrinhos dentro de sala de aula, tem-se como objetivo estabelecer uma aprendizagem significativa do conteúdo abordado e que através de uma sequência didática dinâmica, pretende-se incentivar os alunos a trabalhar em equipes relacionando o que foi aprendido e o que já presenciou em seu cotidiano instigando-o, desta forma, a sua criatividade e tirá-los da comum passividade encontrada, mesmo na hora de se resolver uma questão de física, Cinemática.

Por que escolher a Cinemática como tema desta produção? Em grande parte dos livros didáticos, o conteúdo de física está estruturado como assuntos primeiros: a Cinemática, sendo esta o primeiro contato por parte dos alunos com a física ou no $9^{\circ}$ ano do Ensino Fundamental ou somente no $1^{\circ}$ ano do Ensino Médio. Este primeiro contato irá influenciar a relação entre o aluno e a física e, claro, ao conhecimento científico. Dentro deste contexto, a Cinemática precisa ser apresentada de uma forma mais "degustáveis" e contextualizada sempre que possível para que não o afaste do mundo da ciência.

A história em quadrinho, além de ser um material divertido e interessante tem a incrível capacidade de chamar atenção de crianças a adultos, pois a grande maioria já teve contato com elas e, assim, rememoram momentos de lazer e que ao aluno, quando está interessado, facilita a reflexão e a aprendizagem dos conceitos de física.

O objetivo deste trabalho foi propor uma metodologia de aprendizagem significativa utilizando a história em quadrinhos, como meio de motivar o aluno a criar maneiras diferentes que dêem condições para que adquira o conhecimento de forma relevante relacionando o conhecimento dos conteúdos de física, a formalidade matemática e a confecção/resolução da atividade em forma de quadrinhos, em especial, o interesse pela física e a desmitificação das dificuldades dos exercícios de Cinemática.

\subsection{HISTÓRIAS EM QUADRINHOS}

Histórias em Quadrinhos (HQ's), inserem-se em uma modalidade narrativa onde os diálogos são retratados de forma direta com as personagens, espaço, tempo, o enredo onde a sequência de ações se apresenta, e são representados através de balões, imagens promovendo interações entre as personagens em uma relação de causa e efeito. As imagens representam o fator de destaque de uma HQ e possuem o objetivo variados, mas podemos destacar os de entreter, informar e, também, ensinar. Para isso, há a necessidade de haver a interação imediata entre imagem, conteúdo e leitor [6].

Nasceu como gênero em 1895, graças a criação da tirinha The Yellow Kid, publicada em jornais sensacionalistas de Nova York por Richard Outcault, já se encontrava várias características que tornaram as HQ's mundialmente famosas, como os diálogos em balões, por exemplo. Como disse Feijó (1997) [7], a série de Outcault ganhou status de primeira verdadeira história em quadrinhos. A Figura 1 apresenta a capa da The Yellow Kid, de Richard Outcault.

Com o sucesso das tirinhas de Outcault, na mesma época, surgiram as Comics nos países de língua inglesa e foram consideradas de imediato como categoria de subgênero, principalmente, por causa dos temas abordados fugindo do convencionalismo da época, sendo considerado más influências a crianças e adolescentes. Somente na década de 60 que as HQ's começaram a sair do submundo das artes. A grande revolução das HQ's foi na Histórias de super-heróis como Superman e Batman que foram eternizados na arte sequencial das HQ's e hoje mais famosos ainda com a transportação para a linguagem do cinema, tornando-a mundialmente conhecida. As HQs começaram a ser julgadas sob o ponto de vista estético e passaram ser consideradas como uma manifestação artística [8]. 


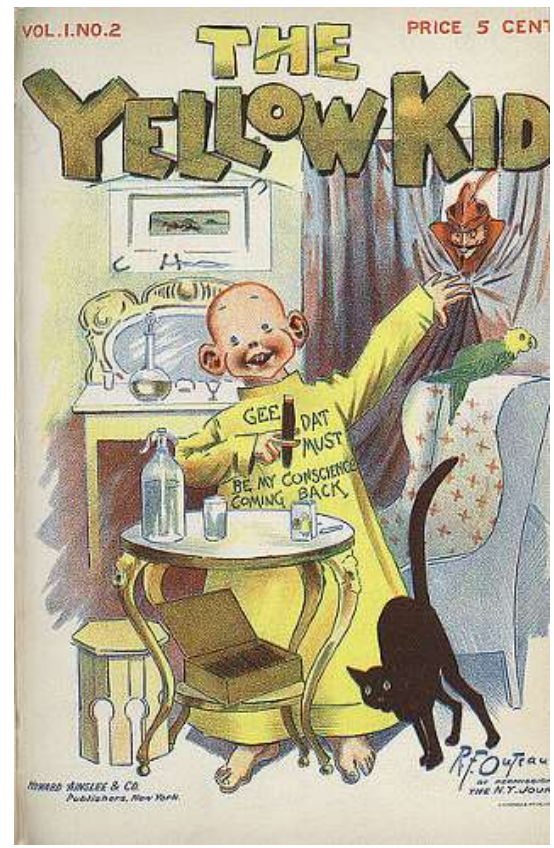

Figura 1: Capa do "The Yellow Kid", do artista americano Richard Outcault. [9].

\subsection{HISTÓRIAS EM QUADRINHOS NO ENSINO DE FÍSICA}

É redundante se falar de que o ensino de física necessita sempre de novas e atraentes metodologias na aplicação dos conteúdos. O ensino deve estar sempre numa busca incessante por novas linguagens que possibilite a ampliação da leitura do mundo e a apropriação desse tipo de linguagem precisa de uma impregnação constante apoiadas por novas e dinâmicas abordagens na forma de se passar o conteúdo programático [10].

$\mathrm{Na}$ atualidade, o aluno vive em uma era de transformações bastante dinâmicas, onde a abordagem puramente expositiva como método de ensino está em conflito direto com a realidade do discente que não se contenta em simplesmente sentar numa carteira e aguardar pacientemente as informações necessárias para se resolver questões propostas e realizando na prática uma ação de puramente substituir números em fórmulas sem a total compreensão do que está sendo proposto.

Desta forma, aluno que tem costume de "memorização de fórmulas" não consegue compreender os conceitos físicos. Ademais, os professores na maioria dos casos se preocupam muito mais em cumprir um determinado programa de ensino do que levantar as ideias previas do aluno sobre um determinado assunto [11].

Diante disso, as HQ's, como proposta de ensino tem como objetivo a diminuição dessa lacuna entre linguagem e a compreensão para resolução de um exercício de um simples trabalho, por exemplo.

Então, a utilização em Física das HQ's podem tornar as aulas mais dinâmicas, já que são instigadoras, interessante e motivadoras, onde a combinação de imagens e texto com linguagem simples e de rápida assimilação inspiram os alunos a lerem e desenvolverem as suas próprias histórias, fazendo com que os alunos passem de meros espectadores a donos da ação que, além de tornar o assunto mais atraente, transforma os alunos em difusores do conhecimento contribuindo para o processo da aprendizagem.

A forma ilustrativa de uma $\mathrm{HQ}$, que tem a função de representar graficamente um fenômeno já estudado, tem uma finalidade, essencialmente, catártica e pode motivar o aluno a buscar novas maneiras de se ver uma questão, o auxiliando no seu entendimento e na sua resolução, graças a sua leitura muitas vezes, torna-se uma leitura de distração e relaxada que é quando menos se espera o leva a uma instigação proporcionada "no decorrer do enredo de uma situação/questão que faça o aluno pensar a respeito do assunto tratado" [12]. 
As histórias em quadrinhos já deixaram de ser vistas como apenas um instrumento de leitura infantil, sendo também uma ferramenta de informação à diferentes áreas, servindo como forma de lazer, repassar e abstrair conhecimento científico e independente da faixa etária [13].

Porém, a utilização das HQ's dentro do ambiente escolar ainda tem um longo caminho pela frente, muito em culpa pela escassa bibliografia e até pode ser utiliza na formação de profissionais neste tipo de abordagem e, ainda, muita das vezes não possui a didática necessária para transmitir os conteúdos através dessa linguagem das Histórias em Quadrinhos. No entanto, o potencial pedagógico delas vem crescendo na educação formal com professores de diferentes níveis de ensino sendo fruto de várias pesquisas acadêmicas no Brasil e no mundo.

A vantagem do uso de HQ's no ensino são várias, pois de forma exitosa a sua linguagem simples de fácil compreensão e ao seu apelo visual, chama a atenção do alunado para uma leitura dinâmica e rápida, demonstrando-se, assim a ludicidade que pode ser extraída através de seu uso dentro de uma sala de aula promovendo o ensino de Física. $\mathrm{O}$ seu uso aliado à uma didática que foge ao formal incentivando a produção de uma HQ ao se resolver uma questão além de articular o conhecimento científico também incentiva uma habilidade artística que pode estar dormente no aluno, tanto no que se refere ao desenho quanto à produção do roteiro escrito do enredo e que de acordo com Caruso e Silveira (2009) [14], isso contribui para a recuperação da autoestima e motivação do aluno a partir da releitura e tradução desse mundo novo com imagens e ciências.

\section{MATERIAL E MÉTODOS}

Este trabalho foi desenvolvido em três etapas: na primeira foi ministrada uma aula abrangendo o Módulo I de Física que tem como tema a Cinemática. Nesta etapa, após toda a exposição do assunto, sanado as dúvidas etc., foram propostos aos alunos a tarefa de resolver algumas questões do referido tema. No final da aula foi analisado o desenvolvimento dos alunos em relação às questões, se houve dificuldade nas resoluções e os "porquês" dessas eventuais dificuldades.

$\mathrm{Na}$ segunda etapa, com o aluno já de posse do conteúdo, analisou-se o conhecimento prévio destes em relação as HQ's interagindo e comentando sobre as favoritas de cada um: quais são as que leem/liam e suas preferidas. Após esse levantamento em sala de aula, em slides, será apresentado o gênero "História em Quadrinhos" e os princípios básicos para a confecção de uma história em quadrinhos, tais como linguagem, organização dos quadros, falas, tipos de balões, onomatopeias, etc.

Apresentado o gênero HQ's, foi demonstrado o uso delas no âmbito escolar como, no caso, HQ's utilizadas na resolução de questões da aula anterior. Desta forma, apresenta-se uma maneira diferente de visualização de uma questão, sendo entregues alguns exemplares à turma para que leiam e se familiarizem com o gênero.

$\mathrm{Na}$ terceira etapa, a turma foi separada em grupos e foi proposta a produção de uma HQ's de questões. Nessa HQ's, eles montaram a história, inventaram personagens e resolveram a questão de uma forma contextualizada com os quadrinhos.

Num primeiro momento, lembrando que ao final da aula anterior foi solicitado que trouxessem réguas e lápis de cor ou cera, a produção dos quadrinhos foi em forma de rascunhos em folha sulfite dentro de sala de aula. Toda a atividade foi acompanhada e ao final foram realizadas as devidas correções e a apresentação da HQ's. Num segundo momento desta etapa, na arte final, foi utilizado a ferramenta "Toondo!" disponível no site http://toondoo.com/MyToondoo.toon.

E, ao final, foram impressos os quadrinhos dos grupos e reunidos em uma única revista que teve um título escolhidos pelos alunos.

O presente trabalho foi desenvolvido com alunos de Ensino Médio da modalidade EJA (Ensino de Jovens e Adultos), do Anexo da Escola Profa. Tereza Donato de Araújo, na cidade de Marabá/PA. Para a coleta de dados, aplicou-se o Termo de Assentimento Livre e Esclarecido (TCLE) com os envolvidos na pesquisa. 


\section{RESULTADOS E DISCUSSÃO}

Os resultados foram obtidos a partir das aulas de Cinemática e das etapas, a saber: apresentação do conteúdo, demonstração e construção das HQ's. Inicialmente observou-se, através do questionário aplicado, o nível de conhecimento dos alunos sobre o tema Cinemática e quais seriam suas maiores dificuldades para assimilar os fenômenos de Física. O resultado já se previa, que seria no que tange a resolução de questões e/ou aos cálculos.

Na etapa que tratou da demonstração de HQ's, se os alunos já tinham conhecimento de alguma HQ's, o resultado foi satisfatório $100 \%$ dos alunos relataram que já tinham conhecimento de HQ's, mas não relacionadaas ao Ensino de Física/Cinemática. Diante disso, apresentou-se com séria importância a ultimação das HQ's como um método de transmitir o conhecimento de maneira divertida e atrativa para os alunos.

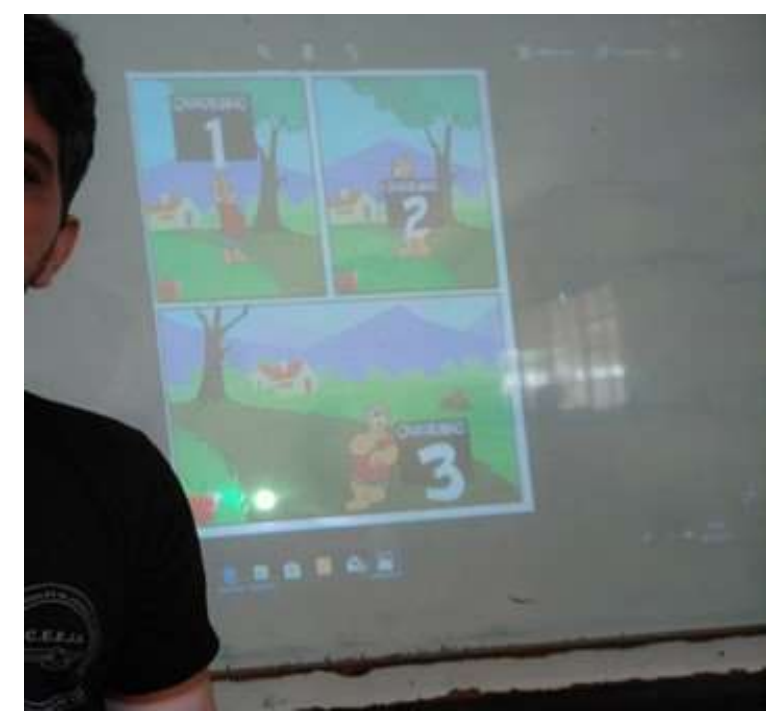

Figura 2: Preparação da HQ.Fonte : Os autores.

Após demonstrar todas as características de uma HQ e como construí-la (Figura 2), foi apresentado um modelo de uma HQ em que contava a história de dois amigos, um urso de nome Milton e uma minhoca que mora dentro de uma maça, chamada Isaque. Nela, eles resolvem uma questão de Física envolvendo velocidade média de um móvel em dois trechos diferentes (Figura $3)$.

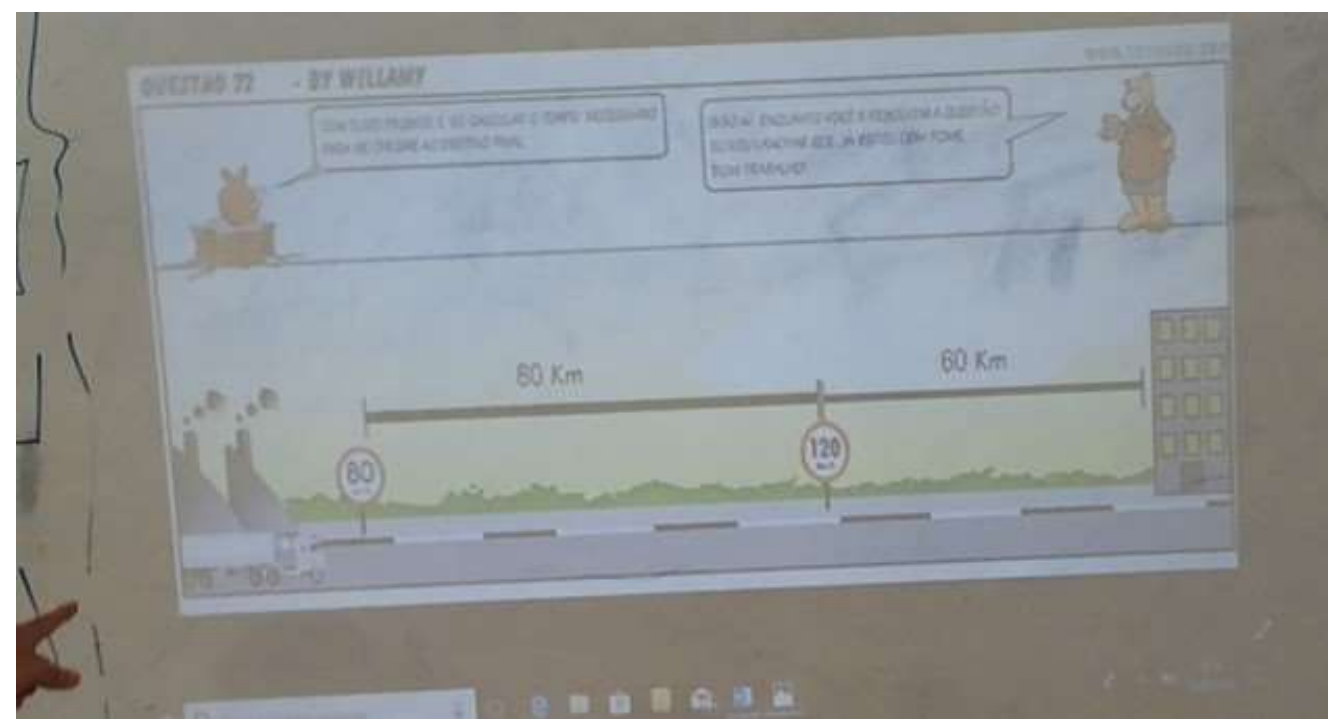

Figura 3: Os personagens Milton e Isaque resolvendo questão de Física em HQ. Fonte: Os autores. 
Após apresentar o gênero $\mathrm{HQ}$, foi entregue alguns exemplares à turma de uma pequena $\mathrm{HQ}$ (Figura 4), que contava a história de dois amigos que resolviam uma questão de física, proveniente do Exame Nacional do Ensino Médio (ENEM) de 2012 [15], para que lessem e se familiarizem com o gênero e tenham o entendimento de que elas podem ser usadas no âmbito escolar, como no caso, na resolução de questões.
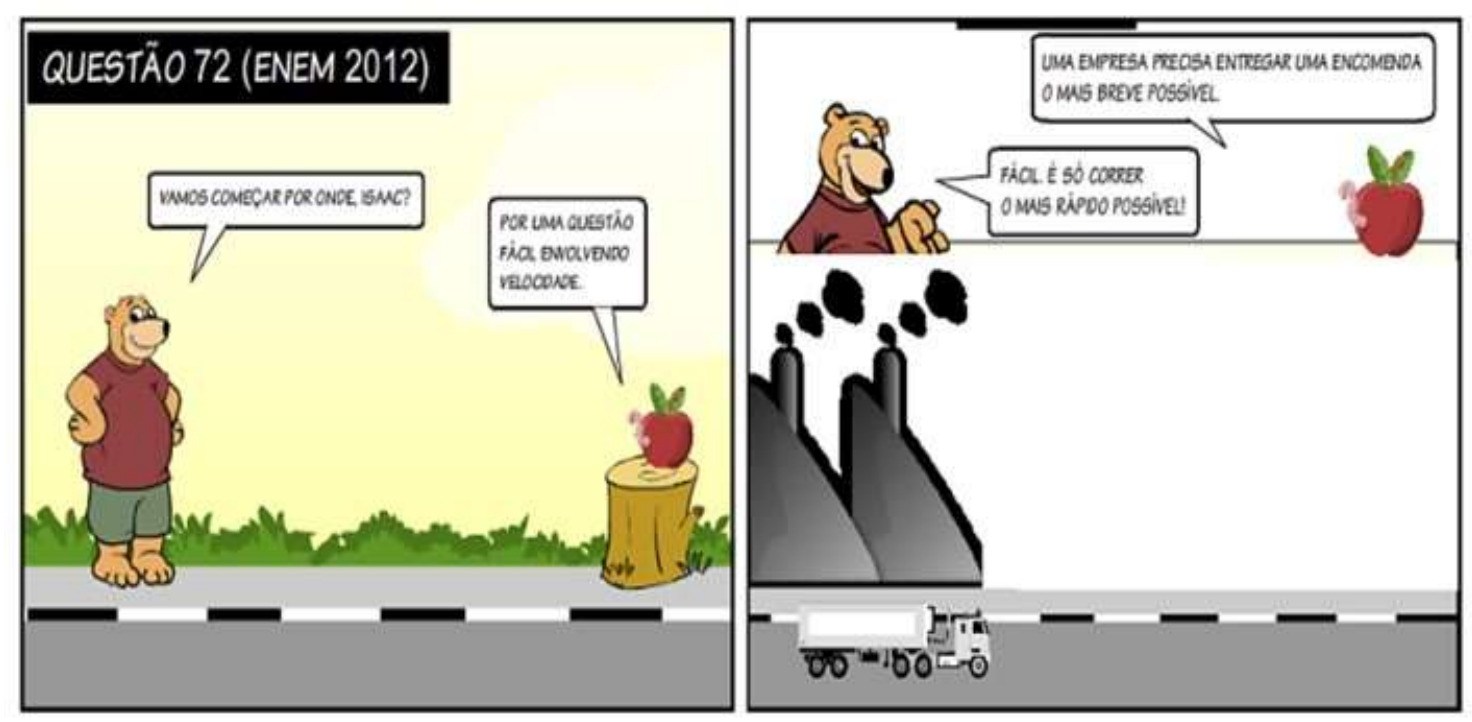

Figura 4: Apresenta a questão 72 do ENEM (2012)[15] em formato HQ.

Com a turma já familiarizada com a "técnica" na confecção de HQ, observou-se que os alunos ficaram mais participativos das aulas de Física. Os alunos relataram que para resolver as questões na forma de HQ torna mais interativo e mais dinâmico e que ajuda a desenvolver o lado criativo. Talvez esse destaque se deve ao fato de que para as resoluções de questões nunca apresentaram outra maneira a não ser a tradicional matemática e suas formalidades estruturais. Portanto, a forma de resolver uma questão de forma diferente, em HQ, torna-se mais interativo e como uma metodologia eficácia para o Ensino de Física.

\section{CONCLUSÃO}

A elaboração de uma História em Quadrinhos teve o seu objetivo atingindo neste trabalho, dando uma maior dinamicidade à prática e de demonstrou ao aluno que por trás de todo problema matemático em física existe uma história e um ambiente ao redor. Diante disso, observou-se que resultados foram satisfatórios relação à aceitação da HQ.

Já supracitado anteriormente, o papel do professor é diversificar e tornar a aula mais dinâmica e interessante a forma de trabalhar o conteúdo e, também, a forma com que se trabalha a resolução de questões. Desta forma, a proposta de se trabalhar com a confecção de Quadrinhos para auxiliar o ensino aprendizagem atende de forma eficaz esse papel, permitindo não só cativar o interesse do aluno na disciplina, como implementar a interdisciplinaridade de assuntos, unindo Ciência Artes - Cálculos. Ciência pelo ensinamento de Física e seus efeitos no cotidiano, Artes no incentivo ao desenvolvimento da habilidade artística e criatividade através da ludicidade, bem como, a formalidade da Matemática em seus Cálculos.

Além disso, a aplicação desta metodologia foi viável em termos de materiais necessários para a sua aplicação. O ideal seria toda escola ter acesso a internet e pelo menos um laboratório de informática, mas com o uso de materiais simples como réguas, lápis de cor, canetas e papel - que são materiais de fácil aquisição e são suficientes para dar andamentos aos trabalhos. Aliado a isso, o uso de HQ's possui fácil aceitação pelos alunos, pois a maioria possui opiniões positivas sobre a leitura, fazendo parte da infância de grande parte deles, o que recorda a uma memória afetiva e já conhecida.

A utilização desta proposta metodológica no aprendizado tornou o ambiente escolar, aula de 
física, a resolução de questões em um ambiente mais dinâmico, descontraído, criativo e agradável conquistando a atenção dos alunos "na parte mais crítica da física"; o uso da matemática e suas fórmulas.

Portanto, as HQ's de Cinemática apresentaram um resultado satisfatório facilitou o aprendizado dos alunos e será uma nova maneira de trabalhar os exercícios de Física, dando-nos uma nova percepção do que acontece ao seu redor e no seu cotidiano escolar.

\section{AGRADECIMENTOS}

Os autores agradecem à CAPES, ao CNPq, ao MNPEF e à Propit/Unifesspa pelo apoio nas pesquisas.

\section{REFERÊNCIAS BIBLIOGRÁFICAS}

1. Braz KM, Fernandes SA. História em Quadrinhos: Um Recurso Didático para as Aulas de Física, 2009. Trabalho apresentado XVIII Simpósio Nacional de Ensino de Física. Vitória, ES. 2009.

2. Vieira EF, Higa I. Histórias em quadrinhos: uma proposta para o ensino de física. Disponível em: <http://educere.bruc.com.br/arquivo/pdf2013/7186_4363.pdf>. Acessado em: 10 de dezembro de 2018.

3. Xavier GKRS. Historias em quadrinhos: panorama histórico, características e verbo-visualidade. Disponível em:<http://www.ufjf.br/darandina/files/2018/01/Artigo-Glayci-Xavier.pdf>. Acessado em: 20 de novembro de 2018.

4. Rauber SC, Medina RD. Trabalhando histórias em quadrinhos como um recurso didático para as aulas de ciências. Disponível em:<https://repositorio.ufsm.br/bitstream/handle/1/759/Rauber_Simone_da_Costa.pdf?sequence=1 $>$. Acessado em: 05 de janeiro de 2018.

5. Pessoa AR. Quadrinhos na educação: uma proposta didática na educação básica [Dissertação]. São Paulo: Instituto de Artes da Universidade Estadual Paulista, São Paulo; 2006, 183p.

6. Vergueiro WPR. Como usar histórias em quadrinhos na sala de aula. São Paulo: Contexto; 2014, 158p.

7. Feijó M. Quadrinhos em ação: um século de história. São Paulo: Moderna, 1997, 79p.

8. Campos MFH, Lomboglia R. HQ: Uma manifestação de arte. In: Luyten SM. (org.). Histórias em Quadrinhos: leitura crítica. 3. ed. São Paulo: Paulina, 1989:10-17.

9. Perez LCA. História da História em Quadrinhos. Disponível em:<https://mundoeducacao.bol.uol.com.br/literatura/historia-historia-quadrinhos.htm〉. Acessado em 05 de janeiro de 2019.

10. Nörnberg IF. Ciência em revista: a construção de conhecimentos científicos através da utilização de histórias em quadrinhos. Disponível em: 〈http://tede2.pucrs.br/tede2/handle/tede/3323〉. Acessado em: 20 de janeiro de 2018.

11. Vitti CM. Matemática com prazer, a partir da história e da geometria. $2^{\mathrm{a}}$ Ed. Piracicaba - São Paulo. Editora Unimep. 1999, 103p.

12. Testoni LA, Abib MLVS. Histórias em quadrinhos e o ensino de física: uma proposta para o Ensino de Inércia. In: Encontro de pesquisa em ensino de física, 9, 2004. Disponível em: <http://www.cienciamao.usp.br/dados/ard/_historiasemquadrinhoseoensinodefisicaumapropostap. arquivo.pdf $>$. Acessado em: 05 de janeiro de 2019.

13. Vergeiro W, Ramos P. Como usar histórias em quadrinhos na sala de aula. São Paulo: Contexto, 2014, $160 \mathrm{p}$.

14. Caruso F, Silveira C. Quadrinhos para a cidadania. História, Ciências, Saúde. 2009; 16(1):217-236.

15. Exame Nacional do Ensino Médio (ENEM). Disponível em: 〈http://download.inep.gov.br/educacao_basica/enem/provas/2012/caderno_enem2012_sab_azul.pdf〉. Acessado em: 20 de janeiro de 2019. 